\title{
As práticas das enfermeiras de uma unidade de saúde da família de Londrina, e a relação com as atribuições do exercício profissional
}

\section{The experience of nurses at a family health unit in Londrina, and its relation to the responsibilities of the professional exercise}

\author{
Suellen Karina de Oliveira Giroti ${ }^{1}$; Elisabete de Fátima Polo de Almeida Nunes ${ }^{2}$. \\ Mara Lúcia Rocha Ramos ${ }^{3}$
}

\begin{abstract}
Resumo
Estudar as práticas de enfermagem é um tema cuja discussão tem sido valorizada e intensificada nos últimos anos, devido à necessidade de se conhecer e esclarecer as competências e dar respaldo ao profissional enfermeiro das práticas realizadas nas Unidades de Saúde da Família (USF). Para isso, torna-se necessário não apenas ter o conhecimento dessas atribuições, mas também saber se todas estão de acordo com a realidade do trabalho desenvolvido por esses profissionais. Esta pesquisa tem uma abordagem qualitativa, tipo estudo de caso, que analisou, durante o período de 19/06/2006 a 06/09/2006, o desenvolvimento das atribuições realizadas por cinco enfermeiras que atuam em uma USF do município de Londrina. Foram utilizadas para este estudo as atribuições estabelecidas pelo Ministério da Saúde (MS) e Autarquia Municipal da Saúde de Londrina (AMS), cujo propósito é entender se as práticas realizadas pelas enfermeiras da USF, condizem com as atribuições propostas pelo MS e AMS. Os resultados mostraram que as atribuições do exercício profissional, embora amplas, direcionam as práticas de enfermagem e estão de acordo com a realidade vivida pelos profissionais em estudo, e umas acontecem com mais intensidade que as outras. Verificou-se que dentre essas atribuições, prevalecem para as enfermeiras do Programa de Saúde da Família (PSF), as atividades assistenciais, e, para a enfermeira coordenadora, as práticas administrativas e de supervisão. Percebe-se que não há a possibilidade de apenas uma enfermeira realizar todas as atribuições preconizadas, havendo a necessidade das enfermeiras trabalharem em equipe, dividindo as tarefas, organizando agendas, realizando planejamento e definindo prioridades para as práticas estabelecidas.

Palavras-chave: Práticas de enfermagem. Trabalho em equipe. Programa de saúde da família.
\end{abstract}

\begin{abstract}
Discussions over nursing practices have been intensified and valued over the last few years, due to the need to know and discuss nursing competences and to provide support to the nursing activities carried out by the Family Health Unit (FHU). For this reason, not only knowing what their responsibilities are but also certifying whether they are connected with the reality of their jobs have become indispensable. A qualitative research, using a case study, was developed to analyze, from June 192006 to September 6 2006, the activities carried out by five nurses from the FHU of Londrina. The nursing attributions analyzed by this research were those established by the Ministry of Health and the County of Londrina Health Department. Results showed that, although the attributions of the nursing professional exercise are broad, they lead to realistic nursing practices, some being more usual than others. In addition,

${ }^{1}$ Enfermeira Especialista em Controle de Infecção em Serviços de Saúde. E-mail: suellenkarina@pop.com.br / suellenkarina@,

2 Doutora em Saúde Coletiva, Docente do Departamento de Saúde Coletiva, Centro de Ciências da Saúde, Universidade Estadual

3 Mestre em Saúde Coletiva pela Universidade Estadual de Londrina. Enfermeira da Secretaria Municipal de Saúde de Londrina.
\end{abstract} hotmail.com. de Londrina.

Semina: Ciências Biológicas e da Saúde, Londrina, v. 29, n. 1, p. 9-26, jan./jun. 2008 
findings from this study showed that, assistance activities, among other attributions, prevailed with nurses from the Family Health Program (FHP), whereas administration and supervision activities are done by the senior nursing officer. It was concluded that these responsibilities cannot possibly be accomplished by only one nurse, and that a good team work is required, with nurses sharing their tasks, organizing diaries, planning and defining priorities for their practices.

Keywords: Nursing practices. Team work. Family health program.

\section{Introdução}

No Brasil, a necessidade de construir novos modelos e práticas de saúde que pudessem dar conta das diversidades dos vários municípios e regiões do país, fez com que, diversas estratégias passassem a ser adotadas a partir da promulgação da Constituição, em 1988 (NEGRI; FARIA; VIANA, 2002).

O Ministério da Saúde (MS) assumiu em 1994, enquanto estratégia setorial para a reorientação do modelo assistencial brasileiro, o Programa de Saúde da Família (PSF) (BRASIL, 2000).

O programa propõe-se a organizar as práticas nas Unidades de Saúde da Família (USF), antigos Postos de Saúde, com a inserção de Equipes de Saúde da Família (ESF), que tem como uma das diretrizes prestar o atendimento integral à população de uma determinada base territorial (NASCIMENTO; NASCIMENTO, 2005).

Entender a Saúde da Família como estratégia de mudança, significa repensar práticas, valores e conhecimentos de todas as pessoas envolvidas no processo da produção social da saúde. Amplia-se a complexidade das ações a serem desenvolvidas pelos profissionais da saúde e, assim, aumentam o limite e suas possibilidades de atuação, requerendo desses profissionais novas habilidades (BRASIL, 2001).

Os profissionais das ESF e das USF, entre eles os enfermeiros, podem desencadear mudanças significativas na área de abrangência e comunidade com quem atuam. Para compreensão das práticas de enfermagem nas USF, é necessário conhecer a definição desta profissão para relacioná-la com as atividades desenvolvidas por ela.
Rosen (1994 apud RAMOS, 2002) cita que o primeiro e mais significativo dos profissionais sanitaristas é a enfermeira de saúde pública. A prática dessas profissionais, segundo o autor, é do final do século XIX e inicia-se na sociedade inglesa, pela necessidade de se combinar ações de educação em saúde e trabalho social, na perspectiva de melhorar o nível de saúde dos pobres. Simultaneamente, iniciase uma outra linha na origem de enfermagem em saúde pública: a prática da visitação sanitária.

De acordo com Rocha e Almeida (2000)

A enfermagem é uma das profissões da área da saúde cuja essência e especificidade é o cuidado ao ser humano individualmente, na família ou na comunidade, desenvolvendo atividade de promoção, prevenção de doenças, recuperação e reabilitação de saúde, atuando em equipes, seja coordenando outros setores para a prestação da assistência e promovendo a autonomia dos pacientes através da educação em saúde (p. 96).

A enfermagem de acordo com Almeida (1991)

é uma ação, ou atividade realizada por homens que precisam dela para reproduzir a sua própria existência e utilizam um saber advindo de outras ciências e de uma síntese produzida por ela própria para aprender o objeto de saúde naquilo que diz respeito ao seu campo específico (cuidado de enfermagem), visualizando o produto final, ou seja, atender as necessidades sociais e no caso da saúde à recuperação do indivíduo, ou o controle da saúde a nível da população (p. 25).

A prática de enfermagem em saúde coletiva configura-se na inter-relação do seu espaço com outras práticas de saúde no seu fazer cotidiano. É influenciada e influencia, transforma, mas também é transformada, sendo vista como uma prática social. Assim, a forma como se organiza, como realiza ou não as ações, determina uma posição de manutenção 
ou de transformação do estado das coisas, da situação de saúde da população e, portanto, não é uma prática neutra (MATUMOTO; MISHIMA; PINTO apud LIMA, 2000).

Para Silva, Nozawa e Silva (2001), os serviços de enfermagem organizam-se em seis áreas principais: administração, coordenação de recursos humanos, educação de pessoal, informática, administração em saúde e vigilância em saúde.

No Município de Londrina, desde o início dos anos 70 , começaram a ser implantados os primeiros postos de saúde do Estado . Desde então, a inserção do enfermeiro nesses serviços tem-se ampliado.

Atualmente, o Município conta com 102 ESF, que atuam em 52 USF, com cobertura de $75 \%$ da população urbana e $100 \%$ da população rural e 13 Equipes de Saúde Bucal (ESB), atuando em 10 unidades de saúde (NERY, 2006).

As práticas propostas para os enfermeiros que atuam na Atenção Básica à Saúde (ABS) estão referidas nos documentos do MS e da Autarquia Municipal de Saúde (AMS). A AMS, para atender uma demanda de enfermeiros das USF e também dos dirigentes da Diretoria de Ações em Saúde (DAS), elaborou em 2000, um documento que define as atribuições das enfermeiras de USF e da gerente da Unidade, possibilitando posteriormente a capacitação dos trabalhadores a partir da reflexão de sua prática (LONDRINA, 2000). Quanto às atribuições propostas pelo MS, as mesmas foram construídas simultaneamente ao processo de elaboração do guia prático do PSF, do qual constam as atribuições comuns à ESF, e as específicas de cada profissional (BRASIL, 2001).

Este trabalho tem como objetivo, analisar as práticas das enfermeiras de uma USF de Londrina, e fazer a relação com as atribuições propostas para as enfermeiras, segundo o MS e AMS. Para isso, serão identificadas práticas desempenhadas intra e extra USF, e as facilidades e as dificuldades para o desenvolvimento dessas atribuições.

\section{Metodologia}

Trata-se de um estudo qualitativo, tipo estudo de caso, que consiste no estudo aprofundado e exaustivo de um ou de poucos casos (uma pessoa, um grupo, uma comunidade), de forma a permitir o seu conhecimento amplo e pormenorizado. A preocupação central deste tipo de pesquisa é a compreensão do caso, que pode ser simples ou complexo, individual ou coletivo, pois constitui uma representação singular da realidade que é multidimensional e historicamente situada (GIL, 2002).

A pesquisa foi realizada em uma USF, localizada no município de Londrina. A Unidade tem uma população de 10000 (dez mil) habitantes cadastrados no Sistema de Informação de Atenção Básica (SIAB) e realiza aproximadamente 25000 (vinte e cinco mil) atendimentos mensais, o que significa um atendimento diário de 350 pacientes/ dia, representando dessa maneira um serviço com uma alta demanda. A USF possui três equipes de PSF, com um total de 2579 famílias cadastradas (LONDRINA, 2006).

Essa Unidade foi escolhida previamente, pois nela estive atuando como interna do $4^{\circ}$ ano de enfermagem, durante o período de 19/06/2006 a 06/09/2006

O estudo foi realizado com cinco enfermeiras, e delas, três atuam nas ESF, uma na coordenação de USF, e uma é enfermeira do período noturno. Para coleta de dados, foram realizadas: observação, diário de campo e entrevistas.

Durante o período de observação, utilizou-se de um ckeck-list para o acompanhamento das práticas desenvolvidas pelas enfermeiras. Deste checklist constavam às atribuições das enfermeiras, estabelecidas pelo MS e AMS, e que eram checadas periodicamente. Posteriormente esses formulários foram analisados e comparados com os dados registrados no diário de campo. 
Nesse check-list, as práticas foram classificadas por categoria, segundo suas características, em: práticas administrativas, aquelas referentes a realização de relatórios, encaminhamentos, guias entre outras; práticas de planejamento, organização e supervisão desenvolvidas na unidade; práticas assistenciais, representadas pelas funções desempenhadas diretamente com ou para o paciente, ou seja, os cuidados diretos prestados pelo enfermeiro ao cliente, como também os cuidados indiretos, participação em programas, visitas domiciliares; práticas educativas e de pesquisas, aquelas relacionadas com a aquisição de novos conhecimentos por parte do enfermeiro, do pessoal de enfermagem, dos agentes comunitários de saúde, e com a comunidade.

Para complementar o estudo, foi aplicado um questionário com questões abertas e questões fechadas às enfermeiras que fizeram parte desse estudo. Foram solicitadas informações referentes ao tempo de formação profissional, e de atividade profissional, experiências na área de saúde pública e questões abertas para que expressassem sua percepção em relação às contribuições, facilidades, e dificuldades nas práticas de enfermagem atribuídas pelo MS e AMS.

À enfermeira que atua no período noturno, foi solicitado que respondesse somente o questionário sobre suas práticas, não sendo realizada a observação de suas atividades.

As atribuições esperadas das práticas das enfermeiras serão apresentadas em forma de figuras (2 a 5). Já aquelas atribuídas que não foram observadas, e/ ou realizadas em menor freqüência durante o período em estudo, serão relatadas no decorrer da apresentação dos resultados e discussão. Não é objetivo desse trabalho apresentar a freqüência das práticas realizadas.

A pesquisa foi autorizada pelo Comitê de Ética e Pesquisa em Seres Humanos do Centro de Ciências da Saúde/ Universidade Estadual de Londrina, parecer $n^{\circ} 098 / 06$. Os participantes da pesquisa assinaram um termo de Consentimento Livre e Esclarecido, solicitando-se sua autorização para a utilização dos resultados do trabalho na pesquisa, e foi esclarecido que seria preservado o anonimato dos mesmos.

\section{Resultados e discussão}

Segundo o documento da AMS (LONDRINA, 2000) e do MS (BRASIL, 2001), as enfermeiras devemrealizarpráticasassistenciais, administrativas, de coordenação, supervisão, gerência e educativas. As enfermeiras que participaram da pesquisa foram enumeradas de 1 a 5, para assim preservar a identificação das mesmas (Quadro 1).

Quadro 1. Caracterização das enfermeiras quanto ao sexo, idade, pós graduação, tempo de formação, tempo de atuação na Rede de Atenção Básica e na USF em estudo. Londrina, 2006.

\begin{tabular}{|c|c|c|c|c|c|c|}
\hline & Sexo & Idade & $\begin{array}{c}\text { Tempo de } \\
\text { Formação }\end{array}$ & $\begin{array}{c}\text { Atuação na } \\
\text { Rede Básica }\end{array}$ & $\begin{array}{c}\text { Atuação na USF } \\
\text { Orlando Cestari }\end{array}$ & Especialização \\
\hline ENF.1 & F & 42 anos & 20 anos & 6 anos & 2 anos & $\begin{array}{c}\text { Formação pedagógica em } \\
\text { enfermagem }\end{array}$ \\
\hline ENF.2 & F & 42 anos & 23 anos & 7 anos & 11 anos & $\begin{array}{c}\text { Formação pedagógica } / \\
\text { obstetrícia }\end{array}$ \\
\hline ENF.3 & F & 38 anos & 14 anos & 14 anos & 2 anos & $\begin{array}{c}\text { Nefrologia e Saúde } \\
\text { coletiva }\end{array}$ \\
\hline ENF.4 & F & 41 anos & 3 anos & 2 anos & 3 anos & $\begin{array}{c}\text { Gerenciamento de serviços } \\
\text { de saúde / saúde coletiva }\end{array}$ \\
\hline ENF.5 & F & 39 anos & 17 anos & 9 anos & &
\end{tabular}


Destas, todas possuem experiência na rede básica de 2 a 14 anos. Quanto ao tempo de serviço na USF em estudo, o menor é de dois anos, e nenhuma enfermeira está em período de estágio probatório, podendo inferir que pelo tempo de atuação nessa USF elas estejam familiarizadas com a equipe de trabalho e conheçam a comunidade com quem trabalham.

Em relação aos cursos de especialização latu sensu, verifica-se que todas possuem pelo menos uma especialização. Três possuem pós-graduação em saúde coletiva, duas possuem especialização em formação pedagógica em saúde:, e duas delas possuem mais de uma especialização. Observouse que todas as enfermeiras que prestam serviço na Unidade possuem formação teórica para atuarem na saúde pública.

As atribuições analisadas serão apresentadas segundo os seguintes tópicos: Práticas assistenciais; Práticas administrativas; Práticas de planejamento, organização e supervisão; Práticas educativas e de pesquisa; Facilidades e dificuldades.

\section{Práticas assistenciais}

Como práticas intra-USF foram consideradas: consultas de enfermagem, assistência a gestante, puérpera, criança, ao idoso, atendimento a demanda, e outros procedimentos de enfermagem. Enquanto prática extra-USF, compreendese: visitas domiciliares em que as enfermeiras realizam assistência, dão orientações de saúde aos pacientes, coletam exames, entre outras atividades. As atividades assistenciais desenvolvidas intra e extra-USF são realizadas em maior número entre as enfermeiras que compõem as equipes de PSF.

Para a realização das atividades assistenciais, elas se organizam por meio de agendas, estabelecendo dias e/ou períodos para prestar assistência à saúde da mulher (planejamento familiar, prevenção de câncer de mama e colo de útero, orientações sobre sexualidade, gestação, pré-natal, puerpério) e a saúde da criança (vacinação, puericultura, controle de peso, alimentação, reações vacinais). $\mathrm{O}$ atendimento à demanda espontânea é realizado quando não estão atuando com suas agendas. As práticas assistenciais elencadas são realizadas diariamente, e sempre que possível prestam cuidados aos pacientes de sua área de abrangência, para, dessa forma, organizar o trabalho e promover uma assistência integral. A Quadro 2 apresenta as práticas assistenciais preconizadas para as enfermeiras da ABS, MS e AMS.

A assistência à saúde da criança de 0 a 5 anos para as crianças saudáveis esta organizada para ser realizada de forma mais sistematizada até a criança completar 18 meses. Já para as de baixo peso, até ganharem peso adequado. Após esse período, as crianças são acompanhadas de acordo com a demanda.

Para assistência ao idoso, não há nenhum programa específico, o que existe é a inclusão desses, em Programas de Hipertensão e Diabetes Mellitus. Outro tipo de atividade é o grupo de caminhada para idosos, período em que estes se reúnem duas vezes por semana na Unidade para verificar a pressão arterial, adquirir medicações, ouvir palestras, fazer alongamentos e a caminhada.

Para que não haja uma sobrecarga da coordenadora com as atividades administrativas e, assim, ela também possa desenvolver cuidados diretos com o paciente, as enfermeiras da ESF organizam-se e alternam-se para a realização das atividades assistenciais diárias. A solicitação de exames complementares, prescrição e transcrição de medicações, só são feitas em caso de rotina como solicitação de exames de glicemia e de pré-natal. Quando o usuário procura o serviço com febre, medicam e em seguida agendam ou encaminham o paciente para consulta médica. 
Quadro 2. Demonstrativo das práticas assistenciais preconizadas para as enfermeiras da Atenção Básica à Saúde, Ministério da Saúde e Autarquia Municipal de Saúde.

1. Realiza cuidados diretos de enfermagem nas urgências e emergências clínicas, fazendo a indicação para a continuidade da assistência prestada.

2. Realiza consultas de enfermagem, solicita exames complementares, prescreve/ transcreve medicações, conforme protocolos estabelecidos nos Programas do Ministério da Saúde e as disposições legais da profissão.

3. No nível de suas competências, executa assistência básica e ações de vigilância epidemiológica e sanitária.

4. Realiza as atividades correspondentes às áreas prioritárias de intervenção na Atenção Básica, definidas na Norma Operacional da Assistência à Saúde (NOAS) 2001.

5. Presta assistência integral à população adscrita respondendo à demanda de forma continua e racionalizada.

6. Executa de acordo com a qualificação de cada profissional, os procedimentos de vigilância à saúde e de vigilância epidemiológica, nas diferentes fases do ciclo de vida.

7. Intervém em áreas de risco.

8. Faz avaliação de enfermagem e garanti encaminhamento adequado.

9. Executa procedimentos (injeção, verificação de PA, curativo, coleta de exames, inalação, etc.).

10. Realiza visita para atendimento no domicílio e busca de faltosos.

11. Executa os programas de Hipertensão Arterial, Diabetes, cardiopatias etc.

12. Desenvolvem assistência nas seguintes áreas: DST/AIDS, dependência química, sexualidade, prevenção de câncer, planejamento familiar, acidentes e violência.

13. Presta assistência à criança vítima de violência.

14. Avalia e acompanha reação vacinal.

15. Presta assistência integral à Saúde da Mulher (climatério, gestante, vítimas de violência, $3^{\circ}$ idade).

16. Faz prevenção de câncer de colo e mama (coleta de Co).

17. Executa o programa de Planejamento Familiar.

18. Executa o programa de Pré-natal de baixo risco e puerpério conforme instruções de trabalho.

19. Participa das campanhas de vacinação, bem como intensifica a vacinação em escolas e empresas.

20. Executa a coleta do teste do pezinho.

21. Presta atenção integral à saúde da criança de 0 a 5 anos; Valorizar a relação com o usuário e com a família, para a criação de vínculo, da confiança, de afeto e de respeito.

22. Desenvolve assistência no Programa de Vigilância ao RN de risco. Alia a atuação clínica à prática da saúde coletiva.

23. Promove ações de acolhimento do adolescente na unidade.

24. Realiza investigação epidemiológica de agravos e acompanha os casos até a alta, bem como investigação de óbito.

25. Realiza ações de prevenção e controle das doenças ocupacionais.

26. Executa o Programa Municipal de Imunizações. 
Em relação aos atendimentos de urgência e emergência que chegam ao serviço, verificou-se que sempre há uma enfermeira atuando em equipe com os demais profissionais. Quando não há a presença dos médicos na Unidade, as enfermeiras recebem o respaldo do Serviço de Atendimento Móvel de Urgência (SAMU), e, por telefone, os médicos desse serviço prescrevem medicações para que elas prestem os primeiros atendimentos ao paciente.

Quanto à vigilância epidemiológica, cada enfermeira que atua no PSF, fica responsável por prestar a assistência e notificar os casos ao serviço. Acompanham rigorosamente esses pacientes até a sua alta, sempre informando a evolução do caso ao serviço responsável pela notificação.

Em relação aos programas existentes na Unidade HIPERDIA, SISPRÉNATAL, Planejamento Familiar, Puericultura, Programa de Vigilância de Baixo Peso, grupo do bebê chiador, grupo de caminhada, Programa de Imunização, grupo de asma, aconselhamento DST/AIDS, prevenção do câncer de mama e de colo de útero, as enfermeiras integrantes das ESF prestam a assistência em sua área de abrangência e junto com as demais enfermeiras, atendem a demanda independente do programa por qual são responsáveis. A exceção é o programa de aconselhamento DST/AIDS, em que há necessidade do profissional possuir o curso de aconselhadores, e apenas uma enfermeira da USF possui este curso.

A realização de procedimentos (injeção, verificação de PA, curativo, coleta de exames, inalação, teste do pezinho, etc.), não são priorizados pelas enfermeiras. Pode-se observar que estas práticas só eram realizadas pelas enfermeiras, quando a Unidade estava com uma demanda muito grande e os demais profissionais necessitavam de ajuda.

As práticas assistências realizadas pelas enfermeiras em estudo envolviam orientações de prevenção de doenças. Esta referência às ações de prevenção é importante, porque é a partir dela que são organizadas medidas que procuram antecipar-se aos agravos e problemas nocivos à saúde.
Entre as práticas assistenciais atribuídas, não se observaram ações dirigidas ao pré-escolar, ao escolar, na assistência a criança e a mulher vítimas de violência, prevenção de câncer de próstata, assistência ao climatério e atividades a dependentes químicos. Segundo relato de uma das enfermeiras, as ações que demandam atenção às vítimas de violência, mulheres e crianças, devem ser realizadas com cuidado, pois podem colocar a própria segurança em risco. $\mathrm{Na}$ atenção aos pacientes dependentes químicos, as enfermeiras contam com outros serviços especializados como: Centro de Apoio Psicossocial (CAPS); CAPS álcool e drogas e o programa de redução de danos.

A prevenção do câncer de próstata e assistência ao climatério, não são práticas desenvolvidas pelas enfermeiras em estudo, pois, segundo elas, essas atividades dependem do acesso à consulta com o médico especialista em urologia e ginecologia, e também há filas de espera para essas especialidades, o que podem ser esses os motivos para a sua não realização.

Foi observado e referido por uma das enfermeiras que o cumprimento de todas as atribuições estabelecidas pelo MS e pela AMS, só são possíveis de serem realizadas, mediante a existência de um trabalho organizado e de equipe entre as enfermeiras com os demais profissionais da USF.

O trabalho em equipe foi referido diversas vezes como necessário para o cumprimento das práticas assistenciais. Verificou-se que nesta USF há um trabalho colaborativo com o envolvimento da maioria dos profissionais (auxiliares e técnicos de enfermagem, agentes comunitário de saúde, médicos, serviços gerais etc).

A Saúde da Família traz para o cenário atual, o trabalho em equipe como uma das condições fundamentais para as mudanças das práticas de saúde na perspectiva da integralidade do cuidado, no entanto, isso não acontece espontaneamente, tampouco é tarefa de fácil resultado. É preciso lembrar que os profissionais que integram uma 
"equipe" são antes de tudo pessoas que tem princípios, valores, interesses e histórias de vida diferentes e, por vezes, conflitantes (MONTEIRO, 2006).

Peduzzi (1998) reconhece o trabalho em equipe, quando há integração e relação recíproca entre as diferentes áreas profissionais, cooperação e articulação das ações multidisciplinares.

As práticas realizadas vão ao encontro com o que se propõe o PSF. Verificou-se que, por meio da assistência de enfermagem, as enfermeiras conhecem melhor a população assistida, suas condições sócioculturais, e com isso têm subsídios para orientar a população sobre sua patologia, como prevenir maiores danos, a como ter melhores condições de saúde, além de conhecer os demais problemas que estão no entorno dos pacientes.

\section{Práticas administrativas}

Emalgunsperíodos, as atribuiçõesadministrativas (Quadro 3) são realizadas com maior freqüência que as demais práticas, devido às exigências e necessidades do serviço. Porém, isso é superado por haver uma boa integração entre as enfermeiras que se organizam dividindo o trabalho.

Quadro 3. Demonstrativo das práticas administrativas preconizadas para as enfermeiras da Atenção Básica à Saúde, Ministério da Saúde e Autarquia Municipal de Saúde.

1. Administra e encaminha ao setor competente, a freqüência dos funcionários.

2. Analisa e realiza a elaboração de relatórios, bem como, encaminhá-los em tempo hábil.

3. Promove ações intersetoriais e parcerias com organizações formais e informais, existentes na comunidade, para o enfrentamento conjunto dos problemas identificados.

4. Garante acesso à continuidade do tratamento dentro de um sistema de referência e contra-referência para os casos de maior complexidade ou que necessitem de internação hospitalar.

5. Participa de comissões de perecer técnico e licitações.

6. Organiza um sistema de informação a nível local (coleta, sistematização, análise, elaboração de fluxo e tomada das decisões).

7. Viabiliza a consulta médica de especialidades priorizando as urgências.

8. Administra situações de conflito/receber reclamações.

9. Procede encaminhamentos em situações especiais (Conviver, Serviço Social...).

10. Executa o SINASC e SISVAN, SISHIPERDIA, SISPRÉNATAL, realizando o controle dos relatórios.

11. Garante o encaminhamento aos CO alterados.

12. Realiza avaliação de desempenho em parceria com a equipe.

A enfermeira coordenadora da USF é responsável pela maioria das atividades administrativas, no entanto algumas atividades são atribuídas e divididas entre as demais enfermeiras de Unidade. Por exemplo, frente ao grande número de relatórios que devem ser processados mensalmente na unidade, estes são divididos entre elas, que ficam responsáveis por entregá-los em tempo hábil à enfermeira coordenadora para encaminhá-los ao nível central da Autarquia.
No atendimento à demanda, as enfermeiras ficam responsáveis por garantir encaminhamento de referência aos pacientes e, sempre que possível, buscar a contra-referência, priorizando as urgências e as situações especiais. Quanto às guias de consulta e encaminhamentos, cada enfermeira é responsável por providenciá-las quando estão realizando essa atividade.

A enfermeira coordenadora fica responsável pelo acompanhamento do registro de freqüência 
de funcionários, escalas de plantões, férias e justificativas de faltas, admissão, demissão e avaliação dos mesmos em período de estágio probatório. As avaliações de desempenhos e resoluções de situações conflitantes na Unidade, são realizadas em equipe com todas as enfermeiras.

As reuniões entre as enfermeiras só acontecem em situações de extrema necessidade, e os problemas mais "simples", são resolvidos por conversas informais entre elas, muitas vezes somente entre duas ou três enfermeiras. Segundo Costa e Shimizu (2005), em um estudo das atividades dos enfermeiros em um hospital escola, as reuniões entre essas profissionais totalizaram apenas $0,3 \%$ do total de atividades administrativas observadas. Isso nos mostra que as enfermeiras não utilizam a reunião como estratégia para a organização do trabalho. A ausência de reunião suprime um momento importante, quando poderiam ser articuladas propostas de ações conjuntas para a comunidade.

As enfermeiras da Unidade observada conseguem trabalhar de forma que atendam às necessidades diárias do serviço, porém a articulação entre as atividades realizadas ainda precisam ser revistas de maneira que a identificação de problemas a serem enfrentados no processo de trabalho possa ser realizada pelo grupo e assim, coletivamente, sejam construídas ações para enfrentamento, de forma que seja significativo para toda a equipe.

A lógica da Educação Permanente em Saúde (EPS) aponta que as reflexões acerca do trabalho em saúde devem acontecer por meio de rodas de discussões, nas quais as relações de poder tornamse horizontalizadas, possibilitando que todos os componentes da equipe transformem-se em sujeitos ativos da ação em saúde (BRASIL, 2003).

Ações intersetoriais e de parceria são realizadas apenas com o serviço social responsável pela região, quando é necessário resolver problemas da comunidade.

Das 12 atividades administrativas observadas apenas as práticas 3 e 5 não são realizadas, as demais ocorreram em maior ou menor intensidade de acordo com a necessidade.

Dentre as atribuições estabelecidas, não foi observado o desenvolvimento da prática de participação das enfermeiras em comissões para emissão de parecer técnico e licitações, sendo relatado por uma das enfermeiras, que este tipo de atividades é realizado pela coordenadora de enfermagem da região.

Práticas de planejamento, organização e supervisão

Para a realização das atividades de planejamento e organização (Quadro 4), a enfermeira coordenadora relatou que houve um trabalho intenso com a equipe interna da USF para a adesão de todos. Verificouse que existem vários programas ativos na Unidade, todos de acordo com as orientações do MS, citados anteriormente. Alguns desses programas necessitam que um grupo de profissionais da Unidade se reúna semanalmente para realizar os aprazamentos, analisarem a participação dos pacientes, organizarem e realizarem busca ativa dos pacientes faltosos, tendo sempre uma enfermeira como referência, que atua junto com os demais membros da equipe. 
Quadro 4. Demonstrativo das práticas de planejamento, organização e supervisão preconizadas para as enfermeiras da Atenção Básica à Saúde, Ministério da Saúde e Autarquia Municipal de Saúde.

1. Coordena e participa do fluxo de informações dentro da equipe.

2. Tem ciência das informações recebidas na USF por meio de reuniões, malote ou mensagens no sistema Hygia e transmiti-las a toda a equipe.

3. Conhece o Estatuto do servidor e torná-lo acessível aos componentes da equipe.

4. Gerencia e garante o acompanhamento adequado aos acidentes de trabalho.

5. Gerencia estágios de alunos de outras instituições de ensino.

6. Controla escala de trabalho em equipe, férias e licenças.

7. Coordena, conduz e integra o trabalho em equipe.

8. Supervisiona e coordena ações para capacitação dos ACS e de auxiliares de enfermagem, com vistas ao desempenho de suas funções.

9. Detecta a necessidade de treinamento e promove sua execução, visando humanização e acolhimento entre equipes e indivíduos.

10. Incentiva a formação e/ou participação ativa da comunidade nos Conselhos Locais de Saúde e no Conselho Municipal de Saúde.

11. Elabora com a participação da comunidade, um plano local para o enfrentamento dos problemas de saúde, e fatores que colocam em risco a saúde.

12. Detecta necessidade de treinamento dos profissionais e planeja a educação permanente em serviço.

13. Acompanha o trabalho da equipe de enfermagem.

14. Realiza o treinamento introdutório na USF.

15. Acompanha e avalia o trabalhador em período de estágio probatório.

16. Defini, junto a equipe, escala de trabalho e férias.

17. Representa a equipe de enfermagem em reuniões e participa de reuniões a nível local.

18. Supervisiona a assistência de enfermagem prestada na USF, serviços gerais e administrativo.

19. Coordena e participa do fluxo de informações dentro da equipe de enfermagem.

20. Planeja o desenvolvimento dos estágios de enfermagem das instituições de ensino realizados na Unidade.

21. Estabelece fluxo de atendimento ao usuário (organizar agendas para atendimento à demanda espontânea e atendimento aos programas, definindo prioridades de acordo com a realidade local).

22. Gerencia o uso de material de consumo e garanti sua adequada utilização (material de limpeza, de higiene pessoal, material de expediente, material médico hospitalar, medicamentos e vacinas).

23. Realiza e participa de avaliação de desempenho.

24. Supervisiona a guarda do material permanente, bem como sua manutenção.

25. Desencadeia ações com base na realidade epidemiológica e social da área de abrangência.

26. Fomenta a participação popular, discutindo com a comunidade conceitos de cidadania, de direitos a saúde e suas bases legais.

27. Coordena o processo de trabalho interno da USF (distribuição de agendas, horários para as atividades, escala de serviço, reuniões de serviço, integração da equipe, fluxo de guias de especialidades).

28. Participa do planejamento e controle das ações de vigilância epidemiológica e sanitáriano seu território;

29. Notifica agravos e problemas ambientais.

30. Controla resumos e medicamentos (estoque, dispensação) relacionados aos programas.

31. Coordena as visitas para atendimento no domicílio e supervisiona a busca de faltosos.

32. Elabora protocolos e instruções de trabalho.

33. Coordena o Programa Municipal de Imunizações.

34. Coordena os programas de Hipertensão Arterial, Diabetes, cardiopatias, etc.

35. Supervisiona e controla o SISHIPERDIA.

36. Coordena a elaboração de relatórios. 
37. Conhece a realidades das famílias pelas quais são responsáveis, com ênfase nas suas características sociais, econômicas, culturais, demográficas e epidemiológicas.

38. Coordena os sistemas de informação referentes aos programas.

39. Organiza as campanhas de vacinação.

40. Supervisiona Sala de Vacinas (controle de estoque de vacinas e rede de Frio).

41. Participa do Comitê de Mortalidade Materna.

42. Participa do comitê de Mortalidade Infantil.

43. Supervisiona a coleta do teste do pezinho e acompanha os resultados.

44. Coordena o programa de Atenção Integral à Saúde da Criança de 0 a 5 anos.

45. Coordena o Programa de Vigilância ao RN de risco.

46. Coordena as atividades de grupos (gestantes, planejamento, familiar, DST/AIDS, aleitamento materno, climatério e $3^{\circ}$ idade).

47. Coordena o programa de Planejamento Familiar.

48. Coordena o programa de Pré-natal de baixo risco e puerpério conforme instruções de trabalho.

49. Coordena o programa de DST/AIDS.

50. Supervisiona os procedimentos (injeção, verificação de PA, curativo, coleta de exames, inalação, etc.).

51. Identifica os problemas de saúde e situações de risco mais comuns aos quais aquela população está exposta.

52. Coordena o SINASC e SISVAN.

As escalas de serviço, organização de materiais, distribuição de tarefa, entre outras, fica principalmente sob a responsabilidade da enfermeira coordenadora. As enfermeiras das equipes ficam responsáveis pela organização e distribuição das tarefas entre os membros integrantes de sua equipe.

As atividades de supervisão na USF são compartilhadas por todas as enfermeiras, embora a enfermeira coordenadora seja a que assume as maiores responsabilidades, que sempre tem uma pessoa de referência para pedir apoio quando necessário.

O termo supervisão se origina das palavras latinas "super" que significa "sobre" e "vídeo" que equivale a "eu vejo". O emprego literal destes termos pode ser interpretado como inspeção; contudo, de sua evolução resultaram novas concepções. A visão moderna associa a supervisão ao controle e educação, propõe uma relação entre parceiros, identifica práticas e instrumentos de atuação conjunta sobre o objeto de trabalho e é denominada "convisão", que significa gestão "co-laborativa" ou construção conjunta. A supervisão deve ser entendida como um processo amplo, complexo, educativo e contínuo, que inclui exame, avaliação, assessoria, informação e intercâmbio dinâmico de conhecimentos e experiências; tarefa que envolve a intersubjetividade e, portanto, múltiplas formas de perceber, sentir, reagir e interpretar situações (REIS; HORTALE, 2004). Essa nova visão é coerente com a proposta do PSF e com a proposta de supervisão das enfermeiras em estudo, pois insere uma nova forma de planejar, agir em saúde, que propicie aos atores envolvidos conscientizarem-se e poderem se envolver no processo de trabalho, no processo de supervisão compartilhada e no processo de "convisão".

Sobre a participação das enfermeiras da Unidade no Comitê de Mortalidade Materna e Infantil, não foi observada a participação de nenhuma delas, porém uma das enfermeiras do PSF relatou que somente quando ocorre uma morte nesta categoria, é que elas são convocadas para juntas ao comitê, analisarem a assistência prestada em nível primário a essa pessoa.

O controle, supervisão e pedido de vacinas e medicamentos são de responsabilidade das enfermeiras e para a realização dessa atividade há 
uma divisão entre elas. Nas campanhas de vacinação, as enfermeiras atendem no horário de funcionamento da USF, não há nenhuma modificação na escala para esta atividade.

Todas as enfermeiras são responsáveis pela organização do fluxo da unidade, e essa organização é baseada na demanda espontânea e no profissional de saúde, porém cabe a enfermeira que atua no primeiro horário da Unidade, organizar as agendas, verificar salas, escala dos funcionários, materiais, verificar equipamentos e medicações.

Em relação ao incentivo da participação da comunidade em conselhos e reuniões para melhoria da saúde local, estas são incipientes. Embora haja participação de uma das enfermeiras enquanto representantes da comunidade nas reuniões do conselho regional e municipal, não há atuação das enfermeiras junto à comunidade local, que segundo foi relatado por uma das enfermeiras "que o bairro não possui um conselho atuante e que a comunidade tem um perfil de esperar muito pelos outros, ou acham, que estas atividades não resolvem muito os problemas".

Quadro 5. Demonstrativo das práticas educativas e de pesquisa preconizadas para as enfermeiras da Atenção Básica à Saúde, Ministério da Saúde e Autarquia Municipal de Saúde.

1. Desenvolve ações junto as creches, asilos, pastorais, escolas, igrejas, conselho tutelar e outras instituições/ organizações.

2. Desenvolve atividades educativas a saúde da terceira idade.

3. Realiza ações educativas nas seguintes áreas: DST/AIDS, dependência química, sexualidade, prevenção de câncer, planejamento familiar, acidentes e violência.

4. Participa das atividades de grupos (gestantes, planejamento, familiar, DST/AIDS, aleitamento materno, climatério e $3^{\circ}$ idade).

5. Executa educação permanente no serviço com os profissionais.

6. Realiza o levantamento epidemiológico de sua área de abrangência.

7. Calcula a cobertura vacinal em nível local, analisa os dados e anota estratégias de intervenção se necessário.

8. Avalia o impacto das ações mediante o perfil epidemiológico. 
O que existe de mais atuante em educação em saúde, é o grupo de caminhada para os idosos, quando são desenvolvidas eventualmente palestras sobre a saúde.

Verificou-se que as atividades educativas individuais são realizadas conforme a demanda ou agendadas nos atendimentos das enfermeiras, como é o caso do planejamento familiar, DST/AIDS, prénatal, puericultura, nas prevenções de câncer de colo de útero e de mama, adolescente, orientação sexual, entre outras atividades.

As atividades educativas com as equipes surgem de acordo com a necessidade que cada enfermeira observa em sua equipe de PSF ou com a equipe interna da USF. Essas atividades são realizadas em horários de menor fluxo da USF.

Este modo de operar as práticas educativas, em que estas não são priorizadas e quando são realizadas partem do olhar de somente um ator, parece seguir os modelos tradicionais de processos educativos realizados para o desenvolvimento dos trabalhadores da saúde, que em geral, destina-se mais a atualização técnica para categorias profissionais específicas, desconsiderando a problematização do processo de trabalho no coletivo e o sentido de equipe de saúde. $\mathrm{O}$ olhar e a escuta que permitem compreender a especificidade de cada problema são necessariamente afetivos e locais, portanto é imprescindível que haja diálogo entre os atores locais (BRASIL, 2005).

Em alguns momentos, foi possível observar que, especialmente, os agentes comunitários de saúde, sentem necessidade de conhecer melhores as doenças que mais acometem sua área de abrangência, saber como lidar com situações conflituosas com os pacientes, comunidade ou equipe de trabalho. A partir deste diagnóstico, são definidos temas para que as enfermeiras integrantes das equipes desenvolvam atividades educativas.

A esse respeito, deve-se ressaltar que a lógica proposta na educação permanente em saúde, além de privilegiar o processo de trabalho como eixo central de aprendizagem, pressupõe discussões conjuntas e participativas sobre os problemas reais do trabalho cotidiano (FRIEDRICH; SENA, 2002). Somente dessa forma pode-se atuar como um potente instrumento de criação de novos conhecimentos que busquem a transformação das práticas de saúde, a autonomia no trabalho, objetivo essencial do ato educativo, e é neste espaço de educação permanente em equipe que surgem oportunidades para construção de um saber coletivo (BRASIL, 2005). No entanto, verificou-se que as atividades educativas não são priorizadas e que estas ainda seguem a lógica tradicional.

As atividades de pesquisa também são pouco realizadas. Em alguns momentos, verificou-se que uma das enfermeiras desenvolve essa atividade realizando estudo de casos, buscando dados e levantando o perfil epidemiológico de sua área de abrangência. As demais enfermeiras relataram falta de tempo para o desenvolvimento de atividades de pesquisa. Observou-se que o Sistema de Informações de Atenção Básica (SIAB), é o principal instrumento utilizado pelas enfermeiras para se ter informações sobre sua área de abrangência, sendo que elas se restringem apenas a sua área de atuação, não tendo uma visão de toda a Unidade. A análise e avaliação da cobertura vacinal foi uma das atribuições que não foi observada durante a pesquisa. Assim, verificase que uma questão tão importante e que previne a população de várias doenças, não é uma atividade realizada sistematicamente pelas enfermeiras.

Segundo Matsumoto, Mishima e Pinto (2001), na saúde pública, a ação de saúde representa o instrumento técnico-político que irá intervir no processo saúde-doença, quebrando sua cadeia casual mediante o tratamento e a reabilitação do indivíduo doente, ou evitando seus riscos e danos por intermédio da prevenção e promoção da saúde, além do controle de sadios. As atividades educativas e de pesquisa colaboram para o desenvolvimento das ações de prevenção e promoção da saúde, para informar a comunidade sobre a prevenção e diminuição de agravos à saúde, e, assim, desenvolver estratégias de ações nos problemas identificados. 
Em nosso cotidiano, vimos que, muitas vezes, essas ações apresentam-se na forma dos programas determinados verticalmente pelo MS. Isto pode ser percebido quando verificamos que das práticas assistenciais observadas, as que acontecem com maior intensidade são as dos programas oficiais existentes, e as demais não são realizadas como por exemplo: em relação à prevenção ao câncer de próstata ou assistência a mulher no climatério, ou, quando realizadas, ocorrem com uma menor intensidade.

\section{Dificuldades e facilidades}

\section{Facilidades}

Quanto aos fatores que facilitam a realização das práticas de enfermagem, quatro das cinco enfermeiras relataram o trabalho em equipe.

A enf 1 relatou que equipe comprometida com o serviço, apesar das inúmeras dificuldades e falta de motivação, não deixam de cumprir sua missão

A enf 4 relatou que o planejamento e a autonomia colaboram muito para o desenvolvimento de suas práticas. Segundo ela, o planejamento das ações a serem desenvolvidas, as distribuições de agendas para as enfermeiras, a organização das visitas e a autonomia para decidir onde, como e quando agir na assistência, colaboram para o desenvolvimento das práticas, realizando-as de forma sistematizada e organizada.

Outras facilidades relatadas por elas foram: um bom relacionamento interpessoal, uma boa interação com a equipe de trabalho e o conhecimento da comunidade. Percebe-se que, dentre todas as facilidades relatadas, salientam-se a interação interpessoal e o trabalho em equipe como uma das principais causas para um bom funcionamento de uma Unidade.

Segundo Sadala (1996), a autonomia refere-se à habilidade da autodeterminação, de ser independente e o seu desenvolvimento se dá pelo processo em que os sujeitos ou grupos humanos ampliam suas capacidades de fazer escolhas de forma livre e esclarecida dos seus próprios desígnios, com a condição de não causar dano ou malefício a outrem ou à sociedade.

As atribuições propostas para as enfermeiras direcionam bem as práticas de enfermagem. Podese perceber como são amplas as atividades prestadas pelas enfermeiras em uma USF, as atribuições condizem com a realidade de suas práticas e dependendo da realidade que compreende a política, a economia e a cultura da região em que atuam, umas são mais realizadas que outras, procurando sempre observar as reais necessidades da comunidade com que trabalham.

\section{Dificuldades}

Quanto aos fatores que dificultam o desenvolvimento das atividades das enfermeiras, foram citadas questões referentes à falta de vontade do gestor, pouco investimento na reestruturação da Unidade, pouca valorização dada aos profissional e baixo nível sócio econômico cultural da clientela (Enf 1 e Enf 5 ).

Ao referir a falta de vontade do gestor, sendo esta uma dificuldade relatada tanto pela Enf 1, quanto pela Enf 5, elas se referiram à falta de investimento na saúde pública, na assistência, em investimentos nos profissionais para uma maior motivação e ficarem na dependência de suas intenções políticas.

Durante a pesquisa, verificou-se o descontentamento de todos os servidores quanto à gestão central, referindo o abandono da Unidade quanto às condições físicas, condições de trabalho inadequadas e falta de investimentos em atualização dos funcionários e até mesmo em relação à remuneração.

Uma das dificuldades sinalizada por uma das enfermeiras, foi quanto ao baixo nível sócioeconômico cultural da clientela. Isto, segundo ela, faz com que os usuários do serviço muitas 
vezes não entendam os limites da atuação dos profissionais. Isso exige muitas vezes soluções para problemas que não são de competência da equipe de saúde, como resolver o problema da demora para as consultas com as especialidades, a falta de recursos financeiros quando os pacientes precisam de tratamentos que não são disponibilizados pelo SUS, problemas que dependem do parecer do serviço social, como os cartões (bolsa escola, família, vale leite etc.) disponibilizados pelo governo federal.

Outras dificuldades foram pontuadas pelas enfermeiras que compõe as ESF, relacionadas ao cotidiano de trabalho:

- falta de recursos materiais e falta de contrareferência (Enf 2);

- falta de equipamentos, materiais, espaço físico e necessidade de contra-referência. (Enf 3);

- a demanda natural, tarefas simples que poderiam ser executadas pelos administrativos e que muitas vezes são realizadas por nós.(Enf 4).

Durante a observação, identificou-se à inexistência de um sistema de contra-referência entre os serviços. Essa debilidade é apresentada pela instituição e citada pelas entrevistadas, causando, segundos elas, dificuldade de acompanhamento da saúde dos pacientes que estão sob responsabilidade das equipes do PSF, dificultando a continuidade da assistência aos pacientes que foram encaminhados para outros serviços.

Faltam materiais freqüentemente para a realização de simples procedimentos e até para a organização da Unidade como os prontuários, fichas e folhas para o atendimento aos usuários.

O espaço físico é um problema bem visível na Unidade, não existe uma sala específica para o atendimento individual de enfermagem, fazendo com que algumas atividades de assistência fiquem prejudicadas, não garantindo a privacidade do paciente, e só podendo ser realizadas em alguns momentos.

Muitos dos atendimentos que as enfermeiras realizam na Unidade são agendamentos de consulta por telefone e solicitação de exames, trabalho esse realizado somente pelas enfermeiras. Esta foi uma das tarefas simples relatada pela Enf 4, na qual ela acha que poderia ser realizada pelo administrativo, pois são práticas não programadas e que quando surgem atrapalham o andamento e a programação do serviço.

Quanto à contribuição das atribuições do exercício profissional para o desenvolvimento das práticas, houve referência pelas enfermeiras de sua importância no esclarecimento das competências e o respaldo ao profissional das práticas realizadas na USF. De acordo com o relato da Enf 1, as atribuições são amplas e com vários direcionamentos, porém no dia a dia não é possível realizar todas as atribuições do exercício, sendo necessário trabalhar em equipe, e delegar atribuições de acordo com as prioridades $\mathrm{E}$ a Enf. 4 concorda que as atribuições são muito amplas e que, cabe ao profissional compreender a expansão e aplicabilidade da prática de enfermagem.

Durante a observação, verificou-se que não há a possibilidade de apenas uma enfermeira realizar todas as atribuições preconizadas, o que acontece é que muitas das práticas desenvolvidas são tidas como prioridades no serviço, como a maioria das atividades assistenciais prestadas a comunidade, visitas domiciliares, relatórios mensais, encaminhamentos, agendamento de especialidades, entre outras.

Segundo Monteiro (2006), o ideal de um trabalho em equipe é que todos estejam envolvidos no processo de produção, que tenham uma visão interdisciplinar, um objetivo comum, compartilhem as decisões e as metas a atingir.

Duas das enfermeiras pesquisadas, (Enf 2 e Enf 3), concordaram parcialmente com as atribuições, e sugerem que é necessário rever algumas práticas que poderiam ser realizadas pelas enfermeiras. 
Podemos inferir que a dependência do aval dos serviços médicos em muitas atividades, além de tomar muito tempo das enfermeiras, pode tornar o cuidado menos resolutivo, uma vez que ações assistenciais de menor complexidade, poderiam ser delegadas para essas profissionais por meio de protocolos clínicos.

Um trabalho realizado em Campinas-SP, em que o autor levantou as práticas das enfermeiras de saúde publica, mostrou que as principais atividades desenvolvidas pelas enfermeiras são os treinamentos e supervisão de pessoal de enfermagem; a assistência e as ações educativas e preventivas nas áreas de criança e adolescente, mulher, adulto e idoso; bem como ações de vigilância epidemiológica e sanitária. Citam-se, ainda, as atividades agrupadas na "cogerência" junto ao coordenador da unidade local de saúde. Quanto às ações dirigidas ao coletivo, são citadas as tradicionais campanhas de vacinação ou as ações de controle de doenças, como a dengue e a cólera, ou as ações de educação em saúde (SILVA; NOZAWA; SILVA, 2001).

Verifica-se que as atividades educativas são prioridades das enfermeiras em Campinas. As atividades de gerência na mesma cidade são pouco realizadas pelas enfermeiras, por não ser característica da cidade ter as enfermeiras como únicas coordenadoras de USF, diferentemente do que ocorre nas USF de Londrina, em que somente as enfermeiras desenvolvem a coordenação das Unidades.

Um trabalho semelhante desenvolvido em um hospital-escola, em que foram observadas 4006 atividades desenvolvidas pelos enfermeiros, $36,1 \%$ corresponderam às atividades administrativas; $32,5 \%$ às atividades assistenciais; $27,3 \%$ às atividades relacionadas ao sistema de informação e apenas $4,1 \%$ às atividades educativas. Isso demonstra que os enfermeiros têm priorizado as atividades administrativas e assistenciais. As atividades educativas não receberam a importância devida pelos enfermeiros, visto que, entre as quatro categorias de atividades estudadas foram às menos desenvolvidas pelos enfermeiros (COSTA; SHIMIZU, 2005).

Em relação às atividades educativas, vimos que está também é uma prática pouco desenvolvida entre as enfermeiras em estudo. Esses dados evidenciam que muitos enfermeiros não realizam estudos em serviço e com a comunidade, sendo está uma prática de fundamental importância para manterem as equipes atualizadas, levarem informações à comunidade e aprimorarem a assistência a serem desenvolvidas aos pacientes.

\section{Conclusão}

Analisar as práticas das enfermeiras na USF permitiu a compreensão de como é rica e complexa a realidade de um serviço ABS. As práticas revelaram estar de acordo com as atribuições propostas pelo MS e AMS de Londrina.

Observou-se que as atribuições das enfermeiras são essenciais para que a assistência atenda as necessidades e as demandas de saúde dos pacientes/ clientes, individual e coletivo, sendo essas práticas interdependentes e articuladas com as práticas dos demais trabalhadores que compõem o serviço.

Foi possível apreender, por meio das observações sistematizadas das atividades desenvolvidas na Unidade, que os enfermeiros integrantes das equipes do PSF têm-se ocupado mais freqüentemente com as atividades assistenciais, e que as atividades de gerência, supervisão e administração da Unidade ficam com maior freqüência sob responsabilidade da enfermeira coordenadora da USF. Verificou-se que o trabalho em equipe, e a integração e interação entre as enfermeiras e equipe favorecem a realização da maioria atribuições estabelecidas.

Os programas estabelecidos pelo MS são os maiores focos de atenção das enfermeiras, e as práticas desenvolvidas pelas enfermeiras, principalmente as do PSF, baseiam-se nos atendimentos aos programas. Quanto à contribuição 
das atribuições para o desenvolvimento das práticas das enfermeiras, pode-se verificar que elas são significativas, pois direcionam e respaldam as atividades realizadas e garantem uma assistência integral aos pacientes e comunidade, se realizadas de forma organizada e em equipe. No entanto, consideram muito amplas as atribuições, e são difíceis de serem operacionalizadas na sua plenitude, considerando a sobrecarga de trabalho a que estão submetidas no cotidiano, ao número de pessoas que compõe equipe e a forma como o serviço esta organizado.

\section{Referências}

ALMEIDA, M. C. P. O trabalho de enfermagem e sua articulação com o processo de trabalho em saúde coletiva: rede básica de saúde em Ribeirão Preto. 1991. Tese. (Livre Docência em Saúde Coletiva) - Escola de Enfermagem de Ribeirão Preto de Universidade de São Paulo, Ribeirão Preto.

BRASIL. Ministério da Saúde. Guia prático do programa de Saúde da Família. Brasília: Fundação Nacional de Saúde, 2001.

. Políticas de educação e desenvolvimento para o SUS: caminhos para a educação permanente em saúde. Brasília: Ministério da Saúde, 2003.

. Secretaria de Gestão do Trabalho e da Educação na Saúde. Curso de formação de facilitadores de educação permanente em saúde: unidade de aprendizagem: práticas educativas no cotidiano do trabalho em saúde. Rio de Janeiro: Ministério da Saúde/ FIOCRUZ, 2005.

Secretaria de Políticas de Saúde. Departamento de Atenção Básica. Programa Saúde da Família. Revista de Saúde Pública, São Paulo, v. 34, n. 3, p. 316-319, jun. 2000.

COSTA, R. A.; SHIMIZU, H. E. Atividades desenvolvidas pelos enfermeiros nas unidades de internação de um hospital-escola. Revista Latino-Americana de Enfermagem, Ribeirão Preto, v. 13, n. 5, p. 654-662, 2005.

FRIEDRICH, D. B. C; SENA, R. R. Um novo olhar sobre o cuidado no trabalho da enfermeira em unidades básicas de saúde em Juiz de Fora-MG. Revista LatinoAmericana de Enfermagem, Ribeirão Preto, v. 10, n. 6, p. 772-779, dez. 2002.
GIL, A. C. Como elaborar projetos de pesquisa. 4. ed. São Paulo: Atlas, 2002.

LONDRINA. Autarquia Municipal de Saúde. Gerência de capacitação de pessoas: atribuições do enfermeiro da autarquia do serviço municipal de saúde de Londrina na unidade básica de saúde. Londrina: Autarquia Municipal de Saúde, 2000.

LONDRINA. Prefeitura Municipal de Londrina. Autarquia Municipal de Saúde. SIAB: Sistema de Informação em Atenção Básica. Londrina: Prefeitura Municipal de Londrina/Autarquia Municipal de Saúde, 2006.

LIMA, J. V. C. A prática de enfermagem em saúde coletiva e o modelo assistencial. 2000. Tese. (Mestrado em Saúde Coletiva) - Universidade Estadual de Londrina, Londrina.

MATUMOTO, S.; MISHIMA, S. M.; PINTO, I. C. Saúde Coletiva: um desafio para a enfermagem. Cadernos de Saúde Pública, Rio de Janeiro, v. 17, n. 1, p. 233-241, fev. 2001.

MONTEIRO, J. M. U. A percepção dos profissionais sobre o trabalho em equipe na saúde da família. 2006. Tese. (Especialização em Saúde da Família) - Universidade Estadual de Londrina, Londrina.

NASCIMENTO, M. S.; NASCIMENTO, M. A. A. Prática da enfermeira no Programa de Saúde da Família: a interface da vigilância da saúde versus as ações programáticas em saúde. Revista Ciência \& Saúde Coletiva, Rio de Janeiro, v. 10, n. 2, p. 333-345, 2005.

NEGRI, B.; FARIA, R.; VIANA, A. L. D. Recursos humanos em saúde: política, desenvolvimento e mercado de trabalho. Campinas: Unicamp/Instituto de Economia, 2002.

NERY, S. R. O Acolhimento no cotidiano dos profissionais das unidades de saúde da família em Londrina - Paraná. 2006. Dissertação. (Mestrado em Saúde Coletiva) Universidade Estadual de Londrina, Londrina.

PEDUZZI, M. Equipe multiprofissional de saúde: a interface entre o trabalho e interação. 1998. Tese (Doutorado em Saúde Coletiva) - Faculdade de Ciências Médicas da Universidade Estadual de Campinas, Campinas.

REIS, C. C. L.; HORTALE, V. A. Programa Saúde da Família: supervisão ou "convisão"? Estudo de caso em município de médio porte. Cadernos de Saúde Pública, Rio de Janeiro, v. 20, n. 2, p. 492-501, abr. 2004. 
ROCHA, S. M. M.; ALMEIDA, M. C. P. O processo de trabalho da enfermagem em saúde coletiva e a interdisciplinaridade. Revista Latino-Americana de Enfermagem, Ribeirão Preto, v. 8, n. 6, p. 96-101, dez. 2000.

RAMOS, M. L. R. O trabalho da enfermeira no serviço municipal de saúde de Londrina. Tese. (Mestrado em Saúde Coletiva) - Universidade Estadual de Londrina, Londrina, 2002. p. 19.
SADALA, M. L. A. Autonomia/mutualidade na assistência de enfermagem. Revista Latino-Americana de Enfermagem, Ribeirão Preto, v. 4, n. 1, p. 111-117, jan. 1996.

SILVA, E. M.; NOZAWA, M. R.; SILVA, J. C. Práticas das enfermeiras e políticas de saúde pública em Campinas, São Paulo, Brasil. Cadernos de Saúde Pública, Rio de Janeiro, v. 17, n. 4, p.989-998, jul./ago. 2001. 